Responsible Editor: Maria Dolores Sánchez-Fernández, Ph.D. Associate Editor: Manuel Portugal Ferreira, Ph.D.

Evaluation Process: Double Blind Review pelo SEER/OJS

\title{
MELGAÇO UM DESTINO RURAL EM CRESCIMENTO: NOVOS DESAFIOS TURÍSTICOS
}

\section{MELGAÇO A RURAL DESTINATION IN GROWTH: NEW TOURIST CHALLENGES}

Lídia Gonçalves Aguiar ${ }^{1}$

IInstitutuo Superior de Ciencias Empresariais e do Turismo

E-mail: laguiar@iscet.pt

(iD)

\begin{abstract}
RESUMO
O mundo rural tem vindo a ganhar uma nova atratividade, fruto da procura turística de quem habita nas grandes cidades e pretende fugir ao stress diário a que está sujeito. No entanto, estes novos turistas necessitam do repouso que o campo Ihes proporciona, mas em simultâneo procuram informar-se culturalmente. O presente artigo pretende demonstrar como o concelho de Melgaço tem condições excecionais para albergar toda esta nova vaga turística. Como concelho de fronteira é extraordinariamente rico em património imaterial, sedimentado em tradições e memórias de contrabando (antes da abertura de fronteira no quadro da EU), bem como património material e natural. Como metodologia, apresenta-se um caso de estudo em que a autora se inseriu na comunidade e recolheu testemunhos da população local, de representantes da autarquia e dos stakeholders. Percorreu todo o concelho e estudou a melhor forma de abrir novos itinerários, consultou os arquivos locais e fez uma exaustiva revisão de bibliografia. Concluiu que o concelho de Melgaço tem as condições excelentes para atingir os objetivos prioritários do Plano Estratégico de Turismo 2027. Neste contexto a autora entende como justificação e pertinência da presente pesquisa o reforço da dinamização do património cultural, do turismo criativo reavivando as suas tradições e da gastronomia deste espaço rural.
\end{abstract}

Palavras-chave: Património Material; Património Imaterial; Turismo Criativo; Turismo de Natureza; Itinerários

\begin{abstract}
The rural world has been gaining a new attractiveness, due to the tourist demand of those who live in the big cities and want to escape from the daily stress they are subject to. Although these new tourists' aim is to relax in an environment that only the countryside can provide, they simultaneously search for cultural information. This present paper intends to demonstrate that the municipality of Melgaço has exceptional conditions to accommodate all this new tourist wave. As a border county it is extraordinarily rich not only in intangible heritage, anchored in traditions and memories related to smuggling (before the opening of the border within the framework of the EU) but also in tangible and natural heritage. As methodology, a case study is presented where the author, in order to better shape and establish new itineraries, inserted herself in the community, collected testimonies from the local population, representatives of the municipality and stakeholders, explored the council area, consulted the local archives and did an exhaustive bibliographic review. It is concluded that the municipality of Melgaço presents excellent conditions to reach the priority objectives of the Strategic Tourism Plan 2027. In this context, the author understands as justification and relevance of the present research the enhancement of its cultural heritage, its creative tourism reviving its traditions, as well as the gastronomy of this rural area. Keywords: Tangible Heritage; Intangible Heritage; Creative Tourism; Nature Tourism; Itineraries
\end{abstract}

How to Cite (APA)

Received on October 03, 2017

Approved on December 27, 2017

Aguiar, L., G. (2018). Melgaço um destino rural em crescimento: novos desafios turísticos. International Journal of Professional Business Review, 3 (1), 69-80. http://dx.doi.org/10.26668/businessreview/2018.v3i1.87 


\section{INTRODUÇÃO}

Melgaço é um concelho que se situa na região norte do país, sub-região do Minho-Lima, distrito de Viana do Castelo. Possui uma área total de cerca de 238 Km2 com 9213 habitantes.

Possui uma longa linha de fronteira: a fluvial (39Km), composta pelo Rio Minho, Rio Trancoso e Rio Laboreiro e a terrestre $(22 \mathrm{Km})$ que se estende ao longo do Planalto do Laboreiro. A sua posição geográfica privilegiada gerou condições propícias, designadamente no decorrer do seculo XX, à emergência de duas realidades que marcaram de forma inequívoca a identidade das suas gentes: o contrabando e a emigração.

Melgaço tem sabido aproveitar as oportunidades que Ihe surgiram com a abertura da fronteira. Hoje a sua economia é ainda muito dependente dos fluxos das remessas dos emigrantes, mas o turismo tem vindo a abrir o território ao exterior, fruto do investimento continuado e insistente da autarquia, em especial, no turismo cultural, ação acompanhada por investidores locais que têm apostado no turismo rural, particularmente no nicho do enoturismo e também no turismo de natureza. Poder-se-á mesmo considerar um caso de sucesso, mas terá de se renovar em permanência, mantendo-se atento às novas demandas turísticas.

Sabendo-se que os novos turistas são cada vez mais exigentes, torna-se necessário um conjunto de propostas que tornem todos os recursos turísticos existentes em atrativos de grande

\footnotetext{
1 "A pesqueira é rocha talhada ou racheada a fogo. Pedra sobre pedra, em bruto ou faceada pelo pico do canteiro. Olhadas de longe, parecem anfractuosidades naturais onde o Minho bate com força, deixando rastos de espuma. De perto, impressionam pelo aspeto ciclópico dos seus altos muros. Escuros e cobertos de panos aparelhados..." In As pesqueiras do Rio Minho de Antero Leite, ed. COREMA." Contam-se no rio Minho mais de 236
}

potencial, seja através de novos itinerários ou da introdução do turismo criativo.

Esta comunicação pretende analisar as possibilidades de evolução do turismo neste território, tendo como metodologia um caso de estudo, já que a autora se inseriu no terreno absorvendo o conhecimento sobre a região vivenciando-a e relacionando-se com a população local, a quem colocou entrevistas. Fez ainda, diversificados contactos com stakeholders locais e representantes da autarquia. Apercebeu-se da importância do turismo para este território rural. Utilizou também uma revisão de bibliografia. Pretendeu, deste modo, atingir o objetivo de valorizar este território seguindo o Plano Estratégico de Turismo, nos seus objetivos prioritários 2027 (Turismo de Portugal, 2017).

\section{Recursos Turísticos e Atividades de Natureza}

Apresenta este concelho, ao nível de paisagem três manchas perfeitamente distintas. A sua zona ribeirinha, ao longo do rio Minho, a meia encosta onde os campos são cultivados em socalcos suportados por muros de pedra e onde se podem encontrar os vinhedos do Alvarinho, num prolongamento em socalcos a partir das margens do rio Minho. Finalmente, bem distinta é a zona montanhosa, parcialmente inserida no Parque Nacional da Peneda-Gerês, parque transfronteiriço Gerês-Xurês, considerado Reserva da Biosfera desde 2009.

O rio Minho, de rara beleza cénica oferece a possibilidade de pesca do salmão, da lampreia e do sável. As pesqueiras ${ }^{1}$ do Rio Minho, inventivas

pesqueiras em utilização e 268 não utilizadas, cuja história remonta à Idade Média. Na sua construção são utilizadas as rochas abundantes na região - granitos de grão grosseiro e seixos, sem qualquer cimento a uni-las. Nas pesqueiras ainda em utilização, pode ser apreciada a técnica de armar a pesca, como a cabaceiras ou botirão. Estas armadilhas são colocadas no caneiro ou boca da pesqueira, com a abertura para jusante, 
armadilhas construídas em pedra nas suas margens com a finalidade de apanhar o peixe, são atualmente um legado histórico vivo da pesca artesanal que sempre se praticou aí e que hoje ainda se pode vivenciar em algumas freguesias ribeirinhas. O rio que sempre representou um fator económico para todo o vale, é atualmente um importante recurso turístico, pela sua fauna e flora que o turista pode aproveitar através de um percurso pedestre ao longo da sua margem, que se encontra devidamente sinalizado e onde encontrará à sua disposição vários painéis explicativos sobre as vivencias de rio, da fauna, da flora e das suas gentes.

É ainda possível, vivenciá-lo com um pouco mais de sentido de aventura, mas com a máxima segurança praticando, através da oferta de serviços de empresas devidamente credenciadas para o efeito, rafting, ou canoagem, entre outros desportos.

Ainda nesta zona ribeirinha é possível visitar algumas quintas e adegas de produção do afamado vinho Alvarinho, vinho verde produzido na sub-região Monção/Melgaço, uma das subregiões mais antigas de Portugal. Ao visitante é proposto um programa educativo pelas adegas que possuem todo um plano de visitas aos vinhedos, com observação de práticas de tratamento e engarrafamento do vinho e explicação sobre os procedimentos para alcançar a sua maturidade. No final, é proposta uma experiencia de degustação acompanhado do fumeiro tradicional da região. O enoturismo, é um produto turístico que tem beneficiado de grandes investimentos de produtores locais, que beneficiaram de alguns programas transfronteiriços, nomeadamente do INTERREG
III. É um produto que vem largamente contribuindo para o desenvolvimento local, aliado ao turismo gastronómico. Para além disso, nos últimos anos, nesta zona ribeirinha estão também a surgir casas disponíveis que se integram no tipo de alojamento TER.

Foi ainda através do INTERREG III que se tornou possível lançar a Rota do Alvarinho, que em muito veio potenciar ao nível turístico esta casta de vinhos; como qualquer rota ela promove e valoriza todo um território com uma vasta oferta desde o alojamento, restauração, comercio, património cultural e material e animação turística. Como refere Almeida (2014) a experiencia vinícola também pode ser vivida em centros urbanos, (no contacto com adegas, caves exposições), embora os turistas que procuram as rotas vinícolas o façam pelo contacto com a paisagem física e cultural, a gastronomia e todo o estilo de vida que lhe está associado.

Situa-se na zona ribeirinha a freguesia rural de Penso que apresenta uma larga tradição no cultivo do linho que atualmente se encontra praticamente extinta. Preservaram-se, no entanto, as suas práticas e os seus saberes e existe igualmente quem cautelosamente tenha guardado os ancestrais instrumentos para o seu tratamento até ficar pronto para ser tecido. A tradição das artesãs de linho é ancestral em Melgaço, mas encontra-se praticamente debelada, pela falta de quem a ela se dedique, pois, os incentivos são poucos e o trabalho é muito. Apresenta-se agora como uma nova atividade, sendo aproveitada como fins turísticos, dado que o tratamento do linho implica uma serie de ciclos de trabalho que podem ser recriados para os turistas em varias 
espocas do ano, rentabilizando assim esta atividade e não se perdendo a tradição.

A freguesia da Gave, já na meia encosta, é também uma das freguesias do concelho melgacense que se destaca pela sua paisagem, tranquilidade e alguma tradição que ainda vem sabendo manter e pelos recursos patrimoniais e geológicos que possui.

Aí sempre se cumpriu a tradição da transumância. Todos os anos, pelo menos desde o seculo XII, no início de maio, os "brandeiros" da Freguesia da Gave subiam com os seus rebanhos para os pastos da Branda da Aveleira, libertando desta forma os terrenos situados a altitudes mais baixas para o cultivo do milho e do feijão. Os rebanhos eram maioritariamente constituídos por gado bovino, ovino, cavalar, e algum caprino.

Por definição, a Branda é o local onde se passa o tempo no verão, altura do ano em que as condições climatéricas são mais "brandas" por oposição ao que sucede durante o Inverno, altura em que os pastores regressam às suas casas na aldeia. Quando a tradição ainda era cumprida, os brandeiros permaneciam na montanha durante todo o verão descendo alguns até á povoação, ao sábado para assistirem á missa de Domingo e levarem mantimentos para a branda.

Foi neste local, abandonado e menosprezado após o abandono desta tradição, que se recuperaram 17 das típicas casas, e se criou um magnífico espaço de turismo de aldeia.

Apesar de oferecer uma série de atrativos turísticos e possuir já um restaurante bem enquadrado na aldeia, carece de oferta adequada de autênticas experiencias rurais e muito particularmente da reinvenção da tradição da transumância. Todos os anos é celebrado o dia do Brandeiro, torna-se por isso fundamental relembrar esta tradição oferecendo-a ao turista através de um evento que lhe permita adquirir este conhecimento, que alia uma peculiaridade desta zona rural a um saber que o visitante interpretará como cultural.

Saliente-se ainda que esta freguesia tem, ao nível da ruralidade, outras potencialidades a desenvolver. O cultivo do milho passa por toda uma serie de ciclos: desde a desfolhada e malhada ${ }^{2}$, passando pela moagem dos grãos de milho e fabrico do pão, tradições que se torna premente "reinventar" como objeto turístico já que esta freguesia rural dispõe ainda de vários moinhos de agua e antigos fornos comunitários para coser o pão, que poderiam ser restaurados o que proporcionaria ao turista uma ambiência de autentico retorno ao passado, oferecendo deste modo mais uma experiencia cultural de enorme riqueza.

A Gave possui outros recursos, já detetados, mas que não estão ainda preparados para serem disponibilizados no contexto da atividade turística. A branda da Aveleira situada a cerca de $1100 \mathrm{~m}$ de altitude, onde o rio Vez se forma com as águas do ribeiro da Aveleira, Vidoeiro e Calçado, é uma zona de montanha marcada pela presença humana, onde são ainda visíveis os vestígios da era glaciar conhecida como "Glaciação de Wurm". Por este facto nesta Branda foi já criado, o primeiro trilho geológico português, uma iniciativa do Instituto Geológico e Mineiro que configura um atrativo para os turistas amantes da natureza, verificando-se ainda a existência de vários estudos geológicos (Lima, 2001).

\footnotetext{
2 A desfolhada e a malhada são trabalhos agrícolas tradicionalmente manuais que se sucedem à apanha do milho e sua preparação para o consumo
} 
Na ótica dos interesses do turista especialista, existe muito perto desta Branda a denominada "Mina do Pedro", antiga mina de volfrâmio e estanho cuja memória de sua atividade nos tempos da II Guerra Mundial perdura no imaginário vivo das populações. Da investigação levada a cabo, verificou-se que esta mina tem o seu primeiro manifesto mineiro datado de 1942, e entre 1959 e 1970 sempre o mesmo proprietário, Pedro Domingos Lourenço, a registou como explorando volfrâmio ${ }^{3}$. Da sua história não foi possível recolher grande informação, restam apenas os netos, que afirmam simplesmente se lembrar de o avô possuir a mina, mas poucas recordações guardaram. Pedro Domingos Lourenço faleceu com 90 anos, em casa de uma neta, na vila de Ponte de Lima.

Um percurso até à Mina do Pedro, proporciona uma panorâmica única e vista deslumbrante sobre a Serra da Peneda que transmite o repouso que a larga maioria dos visitantes da Branda da Aveleira buscam. Em simultâneo, mesmo não se tratando de uma grande mina industrial, com a colocação no local de algumas placas explicativas sobre a importância deste mineral e dos seus usos seria mais uma fonte de conhecimento e abriria a curiosidade para uma experiencia na rota do contrabando de volfrâmio, e ligada intrinsecamente a uma das identidades do povo de todo o concelho de Melgaço, ou seja o contrabando, pois, embora freguesia rural, a Gave é também fronteiriça e todos os seus habitantes também estiveram ligados a esta prática ${ }^{4}$.

\footnotetext{
3 Todos estes registos se encontram no Arquivo Municipal de Melgaço, nos livros de registos mineiros, secção de volfrâmio

4 Esta proposta encontra-se mais detalhadamente apresentada e fundamentada em LAGE, Otília e Lídia Aguiar - Património
}

Subindo até á zona de montanha, deparamonos com a Porta de Lamas, uma das 11 portas de entrada no Parque Nacional da Peneda-Gerês, criado em 1971.

Em 1997 após alguns acordos este parque irá definitivamente juntar-se com o Parque Natural Baixa Limia - Serra do Xurês, tendo em vista o fomento de normas e medidas para a preservação e defesa da fauna, flora e valores paisagísticos dos dois territórios. Criava-se assim o Parque Transfronteiriço de Gerês/Xurês, com uma área aproximada de 100 000ha, maioritariamente granítico e montanhoso, possuidor de um enorme potencial natural e cultural que exige uma colaboração contínua de defesa e valorização.

O Parque possui 5 portas de entrada do lado português e 6 do lado espanhol, cada uma dedicada a um tema. No território de Melgaço situa-se a Porta de Lamas, com o tema "Ordenamento do Território" Estas portas servem como centro de informação turística, tendo ao dispor informação detalhada sobre o seu próprio território, mas igualmente sobre todo o parque transfronteiriço. São por isso locais excelentes para o turista que pretenda fazer uma incursão no parque, tirando informações sobre as atividades e eventos ao seu dispor.

Este parque ainda mantém uma forte presença humana e atrai turisticamente em varias vertentes, sendo a principal a sua vertente paisagística e natural, a que se aliam as paisagens culturais e as tradições ancestrais do povo que ainda aqui habita.

geológico e mineiro e promoção de turismo industrial: Minas portuguesas de Volfrâmio (Melgaço). Comunicação ao II Congresso Internacional sobre Património Industrial: Património, Museus e Turismo Industrial, uma oportunidade para o século XXI - Universidade Católica do Porto - 22 a 24 de Maio de 2014. 
No ano de 2009 este parque foi considerado Reserva da Biosfera Transfronteiriça GerêsXurês, pela UNESCO, e certificado com a Carta Europeia do Turismo Sustentável.

Apresenta-se assim como um território pleno de recursos turísticos onde as experiencias a oferecer aos turistas se se caracterizam pela autenticidade e riqueza cultural.

As potencialidades são inúmeras, como referiu o Dr. Abel Marques, técnico superior de turismo da Camara Municipal de Melgaço, tornando-se necessário que os operadores turísticos consigam aproveitar e oferecer com profissionalismo as experiencias aos turistas. Só assim eles repetem a visita e ainda recomendam o destino. Ainda na opinião do Dr. Abel, vender um produto turístico, trata-se de vender algo intangível, pelo que quem vivenciar com o turista a experiencia terá de saber fazer passar todo o imaginário turístico inerente.

\section{Recursos Culturais e Património Edificado}

A primeira carta de foral foi concedida à Vila de Melgaço, por D. Afonso Henriques em 1185. Pela leitura desta carta, pode-se aperceber que esta povoação era já uma antiga unidade territorial, muito provavelmente uma vila romana ou castro. O modelo do foral, em tudo semelhante ao de Ribadávia, na Galiza, fomentava o ordenamento do território, o seu desenvolvimento económico e defesa já que se tratava de um território fronteiriço (Rodrigues, 1996).

Do antigo castelo resta atualmente a Torre de Menagem, dividida em três pisos e parte da antiga cerca da Vila. A antiga Torre de forma quadrangular, alberga hoje um núcleo museológico onde se pode conhecer um pouco da história e do património arquitetónico desde o período pré-histórico à Idade Contemporânea. Em complemento a este núcleo devem ainda ser visitadas as ruinas arqueológicas da Praça da Republica onde se pode observar vestígios da antiga fortaleza. Para uma boa compreensão do visitante, vão surgindo sucessivos painéis informativos sobre o sistema defensivo da vila (Rocha, 2007).

Na zona histórica da Vila de Melgaço deve ainda ser referenciado o museu do Cinema Jean Loup Passek, instalado no edifício do posto da antiga Guarda-Fiscal, alberga no rés-do-chão uma exposição permanente com objetos raros ligados à arte do cinema e no primeiro andar exposições temporárias. Este espólio cinematográfico é único em Portugal e contém peças raras no Mundo (Rocha, 2007).

Muito embora não seja um museu, o Solar do Alvarinho, aberto ao público desde 1997, é um espaço por excelência para a divulgação desta casta de vinho, bem como de todo o artesanato da região. Instalado num edifício do seculo XVII, denominado "Edifício dos três Arcos" já foi Paços do Concelho e Cadeia Velha.

A fazer a ponte com a parte nova da Vila encontra-se o Museu Memória e Fronteira que tenta retratar a identidade do povo de Melgaço, muito marcado por duas realidades: o contrabando e a emigração. Dividido em dois pisos, apresenta uma exposição dedicada à emigração, desde a preparação da viagem até ao "salto" e chegada ao destino. O contrabando é apresentado por uma exposição de artigos contrabandeados, uma antiga batela, pequeno barco usado pelos contrabandistas para atravessar o rio Minho e ainda por vídeos com a apresentação de "Histórias de Vida" (Esteves, et al., 2007). Saliente-se sobre este museu, a sua interatividade com o público e a reinvenção da tradição de primordial importância que possibilita. 
Como se constatou das entrevistas colocadas aos turistas, os aspetos que apresentam menor grau de conhecimento pelos turistas, são sem dúvida o imaginário de um contrabandista, sendo que nenhum foi capaz de imaginar uma mulher contrabandista.

Já no que se refere à emigração clandestina, embora se verifique o conhecimento deste acontecimento social, poucos sabem enquadrálo socialmente, sendo insignificante o número daqueles que alcançam imaginar uma viagem a pé.

Apresentam-se, assim, dois elementos necessários de suprir para melhor elucidar o visitante do Museu Memória e Fronteira.

Em Castro Laboreiro, já em plena zona de montanha, encontra-se um outro núcleo museológico, este dedicado à etnografia desta vila, onde também se praticou a cultura da transumância à semelhança da freguesia da Gave. No primeiro andar é possível encontrar uma exposição relacionada com as necrópoles megalíticas situadas no Planalto do Laboreiro. Este museu tem um enorme potencial para a recriação de eventos ligados às tradições locais, de enorme riqueza e ancestralidade. Embora inserido no Parque Transfronteiriço, que como já referido tem as suas temáticas adstritas a cada porta, neste caso cabe á porta de Montalegre a recuperação da paisagem natural humanizada, o que tem vindo a fazer, no seu território, pelo que se entende que este museu deve assumir idêntico papel na defesa do seu próprio território, sem que com isso esteja a interferir no trabalho da outra porta. Trata-se de tradições de diferentes aldeias, em que todas elas podem e devem ser preservadas.

\section{1 - Arquitetura Religiosa}

No centro da Vila destaca-se a sua Igreja Matriz, também conhecida por Igreja de Santa Maria da Porta. É um edifício românico, ao que tudo indica datar-se do seculo XII, que foi alvo de sucessivas remodelações. O facto de se chamar igreja Matriz significa ser a principal da terra, pois aqui existiam mais igrejas. É o caso da atual Igreja da Misericórdia, também designada por Santa Maria do Campo. É igualmente um monumento românico que ao longo dos tempos sofreu transformações em toda a sua estrutura. A data da sua construção parece ser do seculo XII, embora só apareça devidamente especificada nas inquirições de D. Afonso III em 1258. O facto de passar para a Misericórdia evitou o seu desaparecimento, como aconteceu com outras Igrejas da Vila (Pintor, 2005).

A Capela de Nossa Senhora da Orada foi construída junto à antiga estrada romana que ligava a orla marítima, sempre junto ao Rio Minho e que passando por Melgaço se dirigia à Galiza. É um belo exemplar românico, datado do seculo XII, foi pertença dos monges do mosteiro de Fiães até á extinção das ordens religiosas. É Monumento Nacional desde 1940, e sofreu obras de restauro em conformidade (Ministério das Obras Publicas e Comunicações, 1940); (Pintor, 2005).

O Mosteiro de Fiães tem data incerta, muitos cronistas afirmam ele já existir no ano 851, mas o primeiro documento que se encontra sobre este mosteiro data de 1142. De origem beneditina viria posteriormente adotar a reforma cisterciense. Várias doações foram concedidas a estes monges, pelo que esta ordem teve grande influência no repovoamento do atual território de Melgaço. É um edifício românico, de que nos resta a igreja, de planta longitudinal, com três naves e quatro tramos. A 
capela-mor com dois tramos, abóboda quebrada e retábulo de talha dourada (Marques, 1990).

O Mosteiro de Paderne terá sido primitivamente ocupado por uma ordem feminina, passando depois para os Cónegos Regrantes de Santo Agostinho. Dada a sua grande antiguidade sofreu muitas alterações. A Igreja possui uma planta em cruz latina, de uma só nava, com um altar em talha dourada. No exterior realça as arquivoltas inteiras da porta de entrada (Pintor, 2005).

A arquitetura românica é extremamente rica no concelho de Melgaço. Pelo que se tornou pertinente a elaboração de um itinerário específico que englobasse os monumentos desta arte, a fim de satisfazer um publico essencialmente de cariz cultural.

\section{2 - Estância Termal do Peso}

As propriedades das águas termais do Peso são reconhecidas desde o seculo XIX.O seu grande impulso verificou-se em inícios de 1884, com a criação da marca Aguas do Peso e o início da construção do seu balneário que, no entanto, para ser uma realidade viria a demorar alguns anos. Este Parque Termal é rodeado por uma frondosa vegetação, constituída por centenários plátanos, tílias e faias, possui dois belos edifícios.
A Buvete e o Balneário, magníficos exemplares da arquitetura do ferro.

As termas foram alvo de requalificação recentemente, constituindo assim mais um atrativo da Vila de Melgaço, na área da saúde e bem-estar.

Refira-se, porém, que a área envolvente ao parque e balneário carece de uma intervenção urbanística de forma a tornar mais atraente esta zona de entrada numa estância que se pode vir a revelar como altamente potenciadora para o turismo local, já que o turismo de saúde e bemestar está em franco desenvolvimento e a requalificação do balneário o colocou a um nível de excelente qualidade. Neste contexto, os acessos pedonais deverão ser repensados, dado que serão utilizados por utentes com mobilidades reduzidas. Com vista a contornar o facto de esta zona possuir um elevado número de edifícios degradados, compreendendo-se que são particulares, sugere-se que sejam colocados painéis, com pinturas evocativas das épocas áureas das Termas do Peso, tapando assim desta forma, estes degradados edifícios e de uma forma simpática criando um ambiente agradável a quem usufrui dos serviços destas termas (Aguiar, 2015)

Mobilidade Turística 


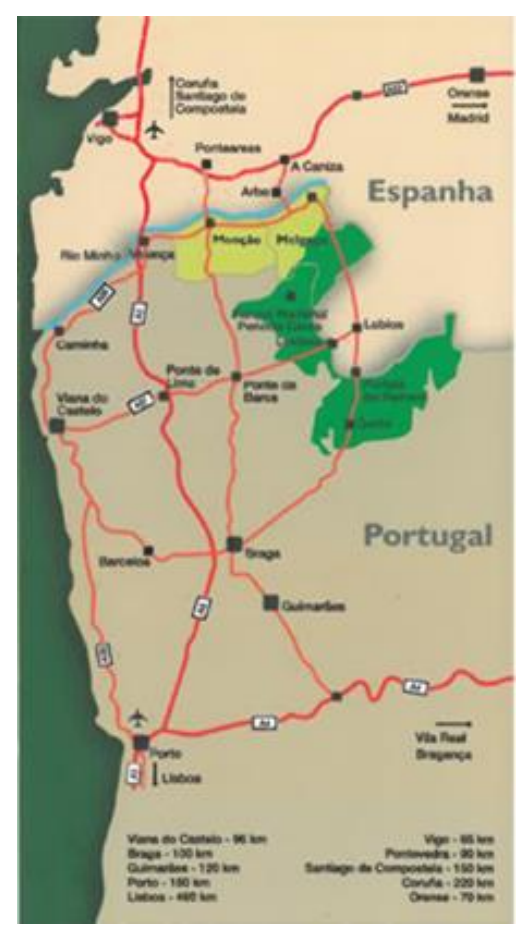

Figura 1. Acessibilidade

Fonte: Câmara Municipal de Melgaço

Como se pode verificar pela cartografia cedida pela Câmara Municipal de Melgaço, este concelho encontra-se numa situação privilegiada no que se refere a acessibilidades. Estas foram fruto dos investimentos feitos pelos governos nacionais, quer no que diz respeito ao Português, quer ao Espanhol, que colocaram Melgaço junto a grandes autoestradas, ficando deste modo este concelho apenas a algumas horas de grandes cidades servidas por aeroportos. Deste modo, como se constata no mapa atinge-se o aeroporto da cidade do Porto, a pouco mais de uma hora e meio de caminho, percorrendo cerca de $150 \mathrm{KM}$, mas se optar utilizar o aeroporto da cidade e Vigo, pouco mais de quarenta minutos de caminho, para percorrer a distância de 65KM.

Porém em relação a Espanha saindo pela ponte que liga Peso a Arbo, na Caniza, poderá entrar na A52 com acesso direto por autoestrada a Barcelona e Madrid. Em relação aos acessos a Portugal, dista apenas $45 \mathrm{Km}$ da autoestrada no3 com acesso ao Porto e continuação direta para
Lisboa e Algarve, passando junto a cidades importantes como Guimarães e Braga.

Todo este contexto apresentado aplica-se somente a quem se desloca em veículo próprio ou para excursões que se movam em viaturas apropriadas. Com efeito, Melgaço não está conectado com o exterior através de uma rede de transportes públicos. Mesmo dentro do próprio concelho, não existe qualquer mobilidade ao nível de transporte publico, salvo o táxi em última instância.

Sabendo-se que o turista "backpacker" (mochileiro) dá primazia à descoberta do território e sua identidade, á sua higiene pessoal deixando o conforto da viagem para segundo plano, afigura-se que Melgaço teria bastante a oferecer a este turista que chega a cidades como Lisboa e Porto e se alojam em Hostels (Rebelo, 2012), mas não acedem a lugares de tradição e rurais como Melgaço, pois não possuem meio de transporte. Saliente-se que o comboio que sai do Porto e se dirige a Vigo, tem paragem em Valença 
do Minho, tornando-se deste modo, no mínimo imprescindível garantir uma ligação desta vila, a $45 \mathrm{KM}$ de Melgaço, de camionete entre o comboio e Melgaço.

Esta realidade pode ser comprovada através das entrevistas aos turistas, sendo que só duas alternativas se nos apresentaram. Ou viajavam em carro próprio, o caso de portugueses ou galegos, ou os vindos de destinos mais longínquos, tinham usados o avião até aos aeroportos do Porto ou Vigo, onde tinham alugado uma viatura.

Dentro da problemática de alcançar novos segmentos turísticos, Melgaço e os seus representantes legais devem debruçar-se sobre esta questão da mobilidade, quer de chegada e partida a Melgaço, quer dentro do próprio concelho, sendo que na atualidade não se justifica, a falta de transportes entre freguesias, principalmente em épocas consideradas "altas" para o turismo sabendo-se da larga oferta de meios alternativos existentes hoje no mercado, passando mesmo pelos mais ecológicos, o que se recomenda vivamente, pelo meio ambiente em que as freguesias se inserem.

4.1 - Análise de dados do Observatório de Turismo de Melgaço

Segundo os dados do Observatório de Turismo de Melgaço, entre 2013 e 2016, aos turistas na sua larga maioria tomaram conhecimento deste destino através de amigos, o que revela a importância do passa a palavra. Surgiram, também, respostas como, uma descoberta fortuita, mas a mais frequente, inclinou-se para a busca na Internet. O uso das agências de viagens é praticamente nulo.

No que diz respeito ao perfil do turista de Melgaço, deteta-se que é maioritariamente português, seguindo-se os provenientes da Galiza. Em 2013 e 2014 situaram-se numa faixa etária entre os 21 e os 50 anos, verificando-se que nos anos de 2015 e 2016 esta faixa sobe para os 30 a 60 anos. Desde 2013 até 2016 predomina os visitantes com profissões intelectuais.

O tempo de permanência é em media de duas noites, despendendo em 2013/2014 uma media de $200 €$ diários que sobe ligeiramente em 2015/2016 para 230€. A sua preferência recaiu sobre a cultura e o património. Verificou-se, ainda, no relatório de 2014 algumas respostas menos positivas para o destino, como a intenção de não regressar nem recomendar.

Apesar de não se notar quebra nas visitas turísticas, os relatórios de 2015 e 2016 denotam a maior exigência do turista atual que espera sempre mais do destino que visita. Torna-se, pois, absolutamente necessário investir em novos itinerários, rotas e no trismo criativo, tal como fomos sugerindo ao longo deste artigo.

A Camara Municipal de Melgaço encetou já um novo programa de Turismo de Natureza, numa tentativa de fomentar esta faixa de turismo que tantas potencialidades tem, face ao Parque Nacional da Peneda Geres, da sua fauna, flora e tradições culturais, inerentes ao facto de ser um território que se mantém humanizado.

4.2 - Analise das entrevistas aos Responsáveis da Autarquia / Stakeholders e População Local

Das entrevistas realizadas aos responsáveis pelo turismo na autarquia de Melgaço, pode-se concluir que existe unanimidade sobre o seu conhecimento das potencialidades do destino que gerem. Todos salientaram a necessidade de maior divulgação/promoção, tendo a responsável pelo pelouro da educação e cultura destacado ser imprescindível a manutenção dos 
espaços públicos devidamente limpos e de ser colocada uma sinalização apropriada aos recursos culturais e monumentos com caracter urgente. Igualmente todos os entrevistados manifestaram que estudos científicos e publicações são sempre benéficos quer na divulgação de Melgaço, mas particularmente no seu contributo para o desenvolvimento do turismo local, pelas novas soluções e sugestões que sempre apresentam. A Câmara Municipal encontra-se, por isso, aberta e apoia todos os investigadores da comunidade académica. Dentro do que o seu orçamento permite tenta implementar as propostas sugeridas.

Ouvidos os stakeolders, todos foram unanimes na urgência em promover e divulgar Melgaço, pelas excelentes condições de trabalho que lhes permite, fruto do meio cultural e natural em que se insere. Em particular a empresa Vertigem e Trilhos, dado trabalhar essencialmente o mercado estrangeiro e se dedicar aos trilhos pedestres, não possuindo guias culturais, encara em dias invernosos enormes dificuldades em aceder aos espaços museológicos, em alternativa à montanha, pois os técnicos aqui de serviço não falam qualquer língua estrangeira. Já para empresas do turismo radical a sua preocupação recai na falta de uma assistência medica rápida e eficaz.

Por último ouviu-se a população local, pois um aumento de fluxos turísticos poderia importunálos na sua vida sossegada e sem ruídos. A realidade é, no entanto, bem diferente pois verificou-se que a população encara o turismo como uma possibilidade de desenvolvimento económico através da criação de mais emprego. Surgem, ainda, os mais nostálgicos que esperam que os turistas tragam a Melgaço a alegria dos tempos do contrabando. Demonstram vontade por partilhar as suas tradições. Por consequência, podemos deduzir que os turistas serão bem acolhidos em Melgaço.

$$
5 \text { - Conclusão }
$$

Este artigo, fruto de um longo trabalho de campo da autora, demonstra as excelentes capacidades do território de Melgaço tem para oferecer ao novo turista. Estes turistas, sempre em busca de novos conhecimentos, não descuram um pouco do descanso e do sossego que o campo thes oferece. É largamente reconhecido por diversos autores que a vida na cidade se torna cada vez mais stressante pelo que a necessidade de procurar a calma da vida rural cresce anualmente. É também verdade que os turistas regressam à cidade para o seu quotidiano, pois é ainda nas grandes urbes que se situam os melhores empregos, cuidados de saúde e mesmo melhor acesso ao ensino.

Mas se viver na cidade permite melhores condições de vida, em contrapartida, usufruir dos recursos do campo e das suas tradições com grande autenticidade, oferece não só o enriquecimento pessoal, bem como dar a conhecer aos mais novos, mundos por eles nunca vividos e que os transporta para realidades absolutamente novas, permitindoIhes uma relação com o mundo rural e uma interpretação destas vivencias nunca pensadas.

Dentro deste contexto, Melgaço tem muito para oferecer a todas as faixas etárias, como se foi descrevendo ao longo do presente artigo, pelo que vivenciar este destino em toda a sua plenitude é uma das hipóteses de ligar o urbano com o rural, aprendendo a viver e interpretar a aldeia.

Nas propostas que se foram colocando ao longo do artigo, foi tido em conta os recursos mais significativos de cada freguesia do concelho 
de Melgaço e em simultâneo tentou-se acompanhar os objetivos traçados pelo Turismo de Portugal no seu documento que projeta os eixos estratégicos do turismo em Portugal até 2027. Deste enlace, pode-se concluir que o destino Melgaço, apresenta excelentes

\section{REFERÊNCIAS}

Aguiar, L. (2015). Routes de la contrebande dans les régions frontalières Galice-Portugal (Melgaço): la muséalisation de la memoire et des traditions. Girona: Universitat de Girona.

Almeida, M. A. (2014). Enoturismo: Fator de Desenvolvimento da Região do Dão Tese de Mestrado. Porto: ISCET.

Esteves, A., \& Sousa, P. (2007). Espaço Museológico Memória e Fronteira Município de Melgaço cit in Jornadas do Contrabando - Actas pp 41-46. Sabugal: Sabugal+,EM.

Lima, J. R. (2001). Olhares multidisciplinares. Melgaço: Câmara Municipal de Melgaço.

Lima, S., \& Partidário, M. (2002). Novos Turistas e a procura da sustentabilidade do Mercado Turístico. Lisboa: Gepe - Gabinete de Estudos e Prespetiva Económica do Ministéro da Economia.

Marques, J. (1990). O Mosteiro de Fiães. Braga: Edição do Autor. capacidades para o desenvolvimento turístico, haja a arte e a vontade de se concretizar na prática projetos criativos sem nunca lhes desvirtuar a historia e as tradições de Melgaço que por ora se mantém autênticas.

Ministério das Obras Publicas e Comunicações. (1940). A Igreja de Nossa Senhora da Orada - Boletim Geral dos Edifícios e Monumentos Nacionais nำ19. Lisboa: Republica Portuguesa - Ministério das Obras Publicas e Comunicações.

Pintor, P. M. (2005). Obra Histórica I. Monção: Rotary Club de Monção.

Rebelo, C. C. (2012). O Turismo Backpacker um retrato em Portugal - Tese de Mestrado. Leiria: Escola Superior de Turismo e do Mar.

Rocha, M. (2007). Melgaço - Memória dos Tempos Passado e Presente. Braga: Do autor com o Patrocinio da Câmara Municipal de Melgaço.

Rodrigues, T. d. (1996). D. Afonso Henriques e o Alto Minho - Revista de Guimarães no106 pp 79-93 Centro de Estudos do Património - Universidade do Minho. Guimarães: Universidade do Minho.

Turismo de Portugal. (2017). Estratégia de Turismo 2027. Lisboa: Republica Portuguesa. 